\title{
Breakfast consumption in Spanish children and young people
}

\author{
Javier Aranceta ${ }^{1, *}$, Lluís Serra-Majem ${ }^{2,3}$, Lourdes Ribas ${ }^{3}$ and Carmen Pérez-Rodrigo ${ }^{1}$ \\ ${ }^{1}$ Community Nutrition Unit, Department of Public Health, Luis Briñas 18, 4th Floor, E-48013 Bilbao, Spain: \\ ${ }^{2}$ Department of Preventive Medicine, University of Las Palmas, Las Palmas, Spain: ${ }^{3}$ Community Nutrition Unit, Park \\ Scientific, University of Barcelona, Barcelona, Spain
}

\begin{abstract}
Background and objectives: Breakfast consumption is important for nutritional balance in all population groups. The objective of this paper is to describe breakfast consumption patterns in Spanish children and young people.

Design: Random population cross-sectional nutritional survey.

Methods: A random sample of 3534 people aged 2 to 24 years were interviewed by a team of 43 dietitians. The protocol included 24-hour recalls (a second 24-hour recall in $30 \%$ of the sample), a food-frequency questionnaire and other questions including lifestyles, knowledge and food preferences.

Results: Participation rate in the survey was 68\%. Of the boys, $91.2 \%$ and $92.2 \%$ of the girls in the sample usually had breakfast. Males aged 18 years and above and 14-17year-old girls showed the lowest consumption rates. Some $4.1 \%$ of the sample did not have any food at all before lunch. Main sources of energy with breakfast were milk and dairy products (34\%) and buns, cookies, croissants, etc. (24.6\%). Some $44.7 \%$ of the sample was classified in the poor-quality breakfast group. Subjects from a low socio-economic background and low educated parents had lower Quality Breakfast Score.

Conclusions: The proportion of children having breakfast before attending school has increased in Spain in recent decades. However, intake of breakfast is not adequate in a large proportion of this population and a number of children and young people still do not eat anything before lunch. School-based nutrition education involving families, teachers and health professionals, supported by community actions, can contribute to improve this situation.
\end{abstract}

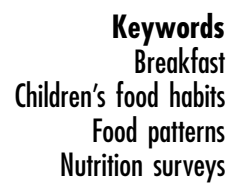

Breakfast consumption is important for nutritional balance in all population groups, but particularly among children, young people and groups at risk such as economically deprived and ethnic minorities as reported by different authors. The prevalence of inadequate intake is lower among children who usually have breakfast compared with those who do not have breakfast ${ }^{1,2}$. Evaluation of school breakfast programmes has built on that evidence ${ }^{3,4}$.

Furthermore, evidence suggests that nutritional intake with breakfast contributes to create a favourable nutritional environment for learning processes and physical performance ${ }^{5,6}$. Nevertheless, it is not clear to what extent breakfast contributes to a better cognitive performance in school. Learning is a complex process resulting from multiple interactions. In fact, social, environmental, as well as emotional and psychological factors play an important role.

In this paper we describe breakfast consumption patterns in Spanish children and young people, the contribution of breakfast to total intake during the day and conditioning factors for having an adequate breakfast.

\section{Methods}

The enKid Study was carried out on a random sample of the Spanish population aged 2-24 years. The National School of Public Health was responsible for sample design. The sample was drafted by a multiple-step sampling procedure based on the population census. Theoretical sample size to allow for 95\% confidence interval (CI) estimates was 5500 subjects, assuming a 70\% response rate.

The study protocol included socio-economic family background, dietary intake by means of 24-hour recall (child with the mother or person responsible for the child's feeding for children younger than 8 years) and a second 24 -hour recall in $25-30 \%$ of the sample. Dietary interviews were performed throughout the year and homogeneously from Monday to Sunday in order to avoid the influence of seasonal as well as day-to-day 
variations. Administration of two 24-hour recalls in a subsample allowed adjustment for random intra-individual variation in intake according to the method described by Liu et al. $^{7}$.

Additionally, a food-frequency questionnaire, questions on dietary habits, consumption of supplements, anthropometric measurements, physical activity in weekdays and leisure time, tobacco and alcohol use, and food preferences, and a questionnaire on basic information regarding food and nutrition were administered.

For the purpose of this paper, breakfast is defined as any intake of food or beverage between $6 \mathrm{a} . \mathrm{m}$. and 10 a.m. during weekdays and between 6 a.m. and 11 a.m. for the weekends and holidays ${ }^{8}$. A Quality Breakfast Score (QBS) was computed by considering consumption of food items from the dairy group, cereal group and fruit with breakfast. According to this scoring system, breakfast was classified as very poor, poor, fair or good quality.

The nutrient database software used for the study consisted of the Spanish database from Mataix et al. ${ }^{9}$, completed with information from the French ${ }^{10}$ and British $^{11}$ food composition tables.

Data analysis was performed using SPSS for Windows version $10^{12}$. Data from the 24-hour recalls were adjusted for intra-individual variability in order to accurately estimate distribution of intakes and percentage of population groups above or below defined cut-off points (Reference Nutrient Intake, RNI) $^{13}$.

Descriptive statistics were computed on the weighted sample. Student's $t$-test was used for comparison of the means between two groups. One-way analysis of variance was used for comparison between more than two groups. The chi-square statistic was computed for comparison of proportions. Log-transformed variables were used as suitable to improve normality as tested by the Kolmogorov-Smirnov test. $P$-values $<0.05$ were considered to indicate an acceptable level of significance.

\section{Results}

Response rate amounted to $70.4 \%$, resulting in a study sample of 3534 individuals: 1629 boys and 1905 girls. The distribution by age and sex of the sample and the study population were not significantly different from the Spanish population for these age groups. Additionally, the distribution by regions maintained their original territoriality.

\section{Usual breakfast consumers}

Of the boys, $91.2 \%$ and $92.2 \%$ of the girls in the sample usually had breakfast. The highest proportion of breakfast consumers was observed in 6-9-year-old boys (98.1\%) and 10-13-year-old girls (99.4\%) $\left(\chi^{2}=81.5 ; P<0.01\right)$. Conversely, $\geq 18$-year-old males $(85.6 \%)$ and $14-17$-yearold girls (89.6\%) showed the lowest consumption rates.
Eight per cent of the sample did not have breakfast usually, just seldom or never at all.

Some $49 \%$ of the group reported having a mid-morning snack. However, $4.1 \%$ of the sample did not have any food at all before lunch; this rate was $9.1 \%$ for $18-24$-yearold males and 5\% for females 14 years and older. The proportion of boys and girls not having any food before lunch was higher among those with lower socioeconomic background (5\%) in comparison with high or medium levels $(3 \%)\left(\chi^{2}=27.4 ; P<0.01\right)$.

\section{Energy and nutrient intake with breakfast}

Average energy intake with breakfast ranged between $283.03 \mathrm{kcal}(1183 \mathrm{~kJ})$ for the $2-5$ year olds and $331.56 \mathrm{kcal}(1385 \mathrm{~kJ})$ for the $14-17$ year olds. Energy intake with breakfast increased with age until 18 years (Snedecor $F=19.39 ; P<0.01$ ). Tables 1 and 2 describe mean energy and nutrient intake with breakfast by age group and gender. This accounts for $18 \%$ of total energy intake, $19.85 \%$ in younger age groups, although percentage contribution to daily intake decreased with age. This proportion was $11.48 \%$ in the $18-24$-year-old group.

Energy intake with breakfast was distributed as follows: protein accounted for $14 \%$, carbohydrate for $51 \%$ and total fat was $34.7 \%$. Saturated fatty acids (SFAs) accounted for $17.4 \%$ of energy intake, monounsaturated fatty acids (MUFAs) were $11.9 \%$ and polyunsaturated fatty acids (PUFAs) were $2.64 \%$. Some $13.8 \%$ of the sample had breakfast intakes according to recommendations, i.e. $25 \%$ of daily energy intake, a lower proportion for the female group.

Higher socio-economic groups and those from families whose parents had higher education levels showed higher proportions of adequate intakes with breakfast (Snedecor $F=4.98 ; P<0.01$ ). Energy intake with breakfast was lower in rural areas compared with urban zones (Snedecor $F=4.17 ; P<0.01$ ). Geographical distribution showed lower intakes with breakfast in the East and South regions of the country $(F=4.57 ; P<0.01)$.

\section{Percentage contribution to energy intake by food groups}

Milk and dairy products provided 34\% of energy intake with breakfast, followed by buns, cookies, croissants, etc. (24.6\%) and other cereal products such as bread or breakfast cereals (20.2\%); sugar (5.25\%); fats and oils (4.45\%); and fruit (3.4\%). Breakfast cereals on average supplied $5.2 \%$ of energy intake, with a higher percentage among 6-14 year olds (7.5\%).

Main sources of fat with breakfast were milk and dairy products (43\%); buns, cookies, etc. (27\%); and added fats (11.9\%).

\section{Foods consumed for breakfast}

A typical breakfast for Spanish children and young people consisted of milk with cocoa powder or soluble chocolate 
Table 1 Energy and nutrient intake with breakfast by age in boys $(n=1629)$, The enKid Study

\begin{tabular}{|c|c|c|c|c|c|c|c|c|c|c|c|c|c|c|c|}
\hline \multirow[b]{3}{*}{ Nutrient } & \multicolumn{15}{|c|}{ Age (years) } \\
\hline & \multicolumn{3}{|c|}{$2-5(n=195)$} & \multicolumn{3}{|c|}{$6-9(n=211)$} & \multicolumn{3}{|c|}{$10-13(n=281)$} & \multicolumn{3}{|c|}{$14-17(n=337)$} & \multicolumn{3}{|c|}{$18-24(n=605)$} \\
\hline & Mean & SD & Median & Mean & SD & Median & Mean & SD & Median & Mean & SD & Median & Mean & SD & Median \\
\hline Energy (kcal) & 283.16 & 152.66 & 265.8 & 331.39 & 171.14 & 319.8 & 371.44 & 229.78 & 361.6 & 384.34 & 283.90 & 386.3 & 334.41 & 283.39 & 341.1 \\
\hline Protein (g) & 9.43 & 3.53 & 9.6 & 10.39 & 4.05 & 10.1 & 11.17 & 5.75 & 11.0 & 11.93 & 7.96 & 11.8 & 10.32 & 10.69 & 10.2 \\
\hline Fat $(\mathrm{g})$ & 11.05 & 7.32 & 9.5 & 13.69 & 9.15 & 10.9 & 15.51 & 11.50 & 13.2 & 16.76 & 15.12 & 14.2 & 14.30 & 14.62 & 13.0 \\
\hline SFA (g) & 5.65 & 3.40 & 5.3 & 6.91 & 4.72 & 5.9 & 7.71 & 5.52 & 7.0 & 7.82 & 6.65 & 6.5 & 6.26 & 6.44 & 5.7 \\
\hline MUFA (g) & 3.74 & 3.37 & 2.9 & 4.69 & 3.60 & 3.5 & 5.23 & 4.39 & 4.1 & 6.13 & 6.81 & 4.7 & 5.45 & 6.40 & 4.0 \\
\hline PUFA (g) & 0.78 & 1.10 & 0.4 & 1.13 & 1.25 & 0.8 & 1.40 & 2.03 & 0.9 & 1.54 & 2.30 & 0.9 & 1.41 & 2.03 & 0.9 \\
\hline Cholesterol (mg) & 39.83 & 31.29 & 35.1 & 47.49 & 36.20 & 36.1 & 51.16 & 45.78 & 42.7 & 54.70 & 57.88 & 43.3 & 52.03 & 64.80 & 39.5 \\
\hline Carbohydrate $(\mathrm{g})$ & 38.31 & 26.06 & 35.8 & 44.08 & 24.83 & 42.9 & 49.68 & 32.95 & 46.8 & 49.28 & 37.01 & 47.0 & 43.72 & 37.68 & 46.1 \\
\hline Fibre (g) & 0.89 & 1.31 & 0.7 & 1.38 & 1.68 & 1.0 & 1.66 & 2.01 & 1.3 & 1.98 & 3.26 & 1.4 & 1.82 & 3.83 & 1.4 \\
\hline Calcium (mg) & 275.46 & 116.33 & 272.5 & 288.31 & 114.98 & 285.6 & 294.34 & 151.08 & 292.4 & 292.22 & 168.88 & 304.9 & 239.67 & 233.08 & 261.0 \\
\hline Iron (mg) & 1.39 & 1.44 & 1.0 & 1.88 & 1.56 & 1.5 & 2.07 & 1.82 & 1.8 & 1.95 & 1.70 & 1.9 & 1.61 & 2.78 & 1.5 \\
\hline Magnesium (mg) & 42.83 & 18.54 & 41.9 & 48.64 & 22.82 & 46.2 & 54.32 & 35.29 & 51.8 & 54.60 & 42.49 & 51.3 & 45.92 & 52.06 & 43.8 \\
\hline Sodium (mg) & 222.94 & 177.24 & 180.6 & 292.25 & 210.28 & 262.8 & 306.64 & 223.56 & 310.0 & 355.65 & 330.45 & 326.5 & 311.46 & 334.62 & 292.8 \\
\hline Potassium (mg) & 397.94 & 144.91 & 397.6 & 418.92 & 142.59 & 414.7 & 456.39 & 220.41 & 447.9 & 451.98 & 261.02 & 448.6 & 395.20 & 319.95 & 410.9 \\
\hline Phosphorus (mg) & 250.16 & 92.99 & 252.1 & 267.61 & 92.75 & 268.4 & 280.81 & 134.12 & 284.2 & 290.91 & 173.31 & 296.1 & 245.25 & 236.10 & 260.3 \\
\hline Vitamin $B_{6}(\mathrm{mg})$ & 0.35 & 0.58 & 0.2 & 0.35 & 0.50 & 0.1 & 0.32 & 0.46 & 0.2 & 0.29 & 0.41 & 0.2 & 0.21 & 0.38 & 0.1 \\
\hline Vitamin $E(\mathrm{mg})$ & 0.37 & 0.37 & 0.3 & 0.47 & 0.54 & 0.3 & 0.67 & 2.29 & 0.3 & 0.70 & 2.24 & 0.4 & 0.63 & 1.54 & 0.3 \\
\hline Thiamine (mg) & 0.30 & 0.42 & 0.2 & 0.30 & 0.35 & 0.1 & 0.28 & 0.32 & 0.2 & 0.26 & 0.29 & 0.2 & 0.21 & 0.29 & 0.2 \\
\hline Riboflavin (mg) & 0.60 & 0.38 & 0.5 & 0.55 & 0.30 & 0.5 & 0.56 & 0.35 & 0.5 & 0.52 & 0.34 & 0.5 & 0.41 & 0.39 & 0.4 \\
\hline Niacin (mg) & 2.00 & 2.74 & 1.1 & 2.56 & 2.67 & 1.6 & 2.78 & 2.86 & 2.1 & 2.55 & 2.58 & 2.0 & 2.23 & 3.72 & 1.8 \\
\hline Folate $(\mu \mathrm{g})$ & 19.85 & 31.45 & 8.0 & 25.55 & 32.14 & 10.0 & 26.16 & 32.69 & 12.0 & 24.18 & 31.55 & 12.1 & 21.31 & 37.62 & 12.0 \\
\hline Vitamin $B_{12}(\mu \mathrm{g})$ & 0.55 & 0.39 & 0.5 & 0.62 & 0.44 & 0.5 & 0.63 & 0.56 & 0.6 & 0.64 & 0.79 & 0.5 & 0.54 & 0.78 & 0.5 \\
\hline Vitamin C (mg) & 15.21 & 29.01 & 1.1 & 8.99 & 18.55 & 0.3 & 11.60 & 22.61 & 0.6 & 10.18 & 21.68 & 0.3 & 13.34 & 31.07 & 0.3 \\
\hline Vitamin A $(\mu \mathrm{g})$ & 118.35 & 114.56 & 99.1 & 118.34 & 77.23 & 99.1 & 145.84 & 299.78 & 101.9 & 131.32 & 111.13 & 123.7 & 117.89 & 151.38 & 99.1 \\
\hline Vitamin D $(\mu \mathrm{g})$ & 0.45 & 0.82 & 0.1 & 0.57 & 0.78 & 0.1 & 0.50 & 0.76 & 0.1 & 0.50 & 0.79 & 0.1 & 0.47 & 1.00 & 0.1 \\
\hline
\end{tabular}

SD - standard deviation; SFA - saturated fatty acid; MUFA - monounsaturated fatty acid; PUFA - polyunsaturated fatty acid.

Table 2 Energy and nutrient intake with breakfast by age in girls $(n=1905)$, The enKid Study

\begin{tabular}{|c|c|c|c|c|c|c|c|c|c|c|c|c|c|c|c|}
\hline \multirow[b]{3}{*}{ Nutrient } & \multicolumn{15}{|c|}{ Age (years) } \\
\hline & \multicolumn{3}{|c|}{$2-5(n=190)$} & \multicolumn{3}{|c|}{$6-9(n=212)$} & \multicolumn{3}{|c|}{$10-13(n=286)$} & \multicolumn{3}{|c|}{$14-17(n=345)$} & \multicolumn{3}{|c|}{$18-24(n=872)$} \\
\hline & Mean & SD & Median & Mean & SD & Median & Mean & SD & Median & Mean & SD & Median & Mean & SD & Median \\
\hline Energy (kcal) & 291.00 & 199.67 & 277.1 & 291.12 & 142.50 & 282.2 & 289.95 & 157.66 & 290.0 & 280.00 & 203.89 & 275.2 & 269.17 & 192.72 & 274.3 \\
\hline Protein (g) & 10.01 & 5.10 & 9.6 & 9.57 & 3.98 & 9.6 & 9.46 & 4.56 & 9.8 & 9.21 & 6.06 & 9.3 & 8.84 & 6.20 & 9.3 \\
\hline Fat (g) & 11.27 & 8.07 & 9.9 & 12.62 & 8.10 & 10.5 & 11.94 & 8.41 & 10.9 & 11.16 & 10.90 & 9.4 & 10.75 & 10.24 & 9.3 \\
\hline SFA (g) & 5.85 & 3.61 & 5.4 & 6.49 & 3.82 & 5.9 & 6.11 & 4.13 & 5.9 & 5.44 & 5.67 & 5.0 & 4.72 & 4.67 & 4.5 \\
\hline MUFA (g) & 3.68 & 3.55 & 2.9 & 4.31 & 3.49 & 3.3 & 4.00 & 3.23 & 3.3 & 3.91 & 4.13 & 3.2 & 4.06 & 4.41 & 3.1 \\
\hline PUFA (g) & 0.76 & 1.20 & 0.4 & 0.90 & 1.16 & 0.6 & 0.90 & 1.10 & 0.5 & 0.92 & 1.22 & 0.6 & 1.07 & 1.50 & 0.7 \\
\hline Cholesterol (mg) & 35.31 & 30.88 & 33.5 & 39.77 & 26.73 & 36.1 & 36.39 & 30.94 & 30.0 & 36.48 & 39.26 & 28.9 & 35.48 & 42.75 & 28.9 \\
\hline Carbohydrate (g) & 39.28 & 33.56 & 35.7 & 36.93 & 19.54 & 35.7 & 38.40 & 23.72 & 37.0 & 37.94 & 27.81 & 38.1 & 36.55 & 25.60 & 36.6 \\
\hline Fibre (g) & 0.87 & 1.42 & 0.6 & 1.10 & 1.71 & 0.9 & 1.22 & 2.12 & 0.8 & 1.42 & 2.31 & 1.0 & 1.65 & 2.40 & 1.1 \\
\hline Calcium (mg) & 275.13 & 129.94 & 264.2 & 267.33 & 99.45 & 278.7 & 258.02 & 122.22 & 267.8 & 236.06 & 154.32 & 261.8 & 218.74 & 144.36 & 253.0 \\
\hline Iron (mg) & 1.31 & 1.37 & 1.0 & 1.55 & 1.38 & 1.2 & 1.60 & 1.53 & 1.3 & 1.45 & 1.30 & 1.3 & 1.35 & 1.20 & 1.2 \\
\hline Magnesium (mg) & 45.72 & 30.00 & 41.8 & 46.63 & 21.67 & 46.4 & 48.20 & 25.44 & 48.2 & 45.73 & 30.26 & 46.6 & 44.50 & 32.53 & 42.7 \\
\hline Sodium (mg) & 217.20 & 196.48 & 162.4 & 232.70 & 199.12 & 191.1 & 236.64 & 206.26 & 201.2 & 258.83 & 264.86 & 205.6 & 242.32 & 241.07 & 195.0 \\
\hline Potassium (mg) & 403.53 & 192.04 & 390.3 & 404.96 & 152.28 & 414.0 & 405.61 & 174.17 & 415.4 & 381.95 & 217.48 & 408.4 & 368.67 & 225.60 & 388.3 \\
\hline Phosphorus (mg) & 260.74 & 116.58 & 257.8 & 259.70 & 92.90 & 270.2 & 253.05 & 118.76 & 269.2 & 239.45 & 147.42 & 254.1 & 228.82 & 152.24 & 248.5 \\
\hline Vitamin $B_{6}(\mathrm{mg})$ & 0.29 & 0.37 & 0.1 & 0.28 & 0.38 & 0.1 & 0.25 & 0.37 & 0.1 & 0.22 & 0.31 & 0.1 & 0.21 & 0.27 & 0.1 \\
\hline Vitamin E (mg) & 0.46 & 0.67 & 0.3 & 0.48 & 0.71 & 0.3 & 0.46 & 0.66 & 0.3 & 0.47 & 0.63 & 0.3 & 0.55 & 0.97 & 0.3 \\
\hline Thiamine (mg) & 0.27 & 0.34 & 0.1 & 0.23 & 0.25 & 0.1 & 0.22 & 0.26 & 0.1 & 0.20 & 0.22 & 0.1 & 0.18 & 0.19 & 0.1 \\
\hline Riboflavin (mg) & 0.60 & 0.49 & 0.5 & 0.53 & 0.35 & 0.5 & 0.48 & 0.29 & 0.5 & 0.42 & 0.31 & 0.4 & 0.40 & 0.35 & 0.4 \\
\hline Niacin (mg) & 1.79 & 1.88 & 1.0 & 2.16 & 2.66 & 1.3 & 2.09 & 2.37 & 1.4 & 2.17 & 2.43 & 1.7 & 2.29 & 2.56 & 1.8 \\
\hline Folate $(\mu \mathrm{g})$ & 17.07 & 20.96 & 7.2 & 20.96 & 25.49 & 10.6 & 21.10 & 26.80 & 11.0 & 20.72 & 25.51 & 12.0 & 20.95 & 26.20 & 12.8 \\
\hline Vitamin $B_{12}(\mu \mathrm{g})$ & 0.54 & 0.29 & 0.5 & 0.52 & 0.27 & 0.5 & 0.53 & 0.34 & 0.5 & 0.61 & 1.84 & 0.5 & 0.50 & 0.59 & 0.5 \\
\hline Vitamin C (mg) & 15.45 & 31.98 & 1.3 & 9.59 & 20.91 & 0.3 & 10.73 & 22.53 & 0.3 & 12.56 & 26.57 & 1.0 & 14.55 & 31.38 & 1.1 \\
\hline Vitamin A $(\mu \mathrm{g})$ & 103.06 & 70.88 & 99.1 & 117.83 & 77.46 & 99.2 & 104.06 & 77.88 & 99.1 & 92.64 & 98.77 & 99.0 & 88.87 & 89.43 & 89.2 \\
\hline Vitamin D $(\mu \mathrm{g})$ & 0.36 & 0.59 & 0.1 & 0.44 & 0.68 & 0.1 & 0.41 & 0.65 & 0.1 & 0.36 & 0.72 & 0.1 & 0.40 & 0.78 & 0.1 \\
\hline
\end{tabular}

SD - standard deviation; SFA - saturated fatty acid; MUFA - monounsaturated fatty acid; PUFA - polyunsaturated fatty acid. 


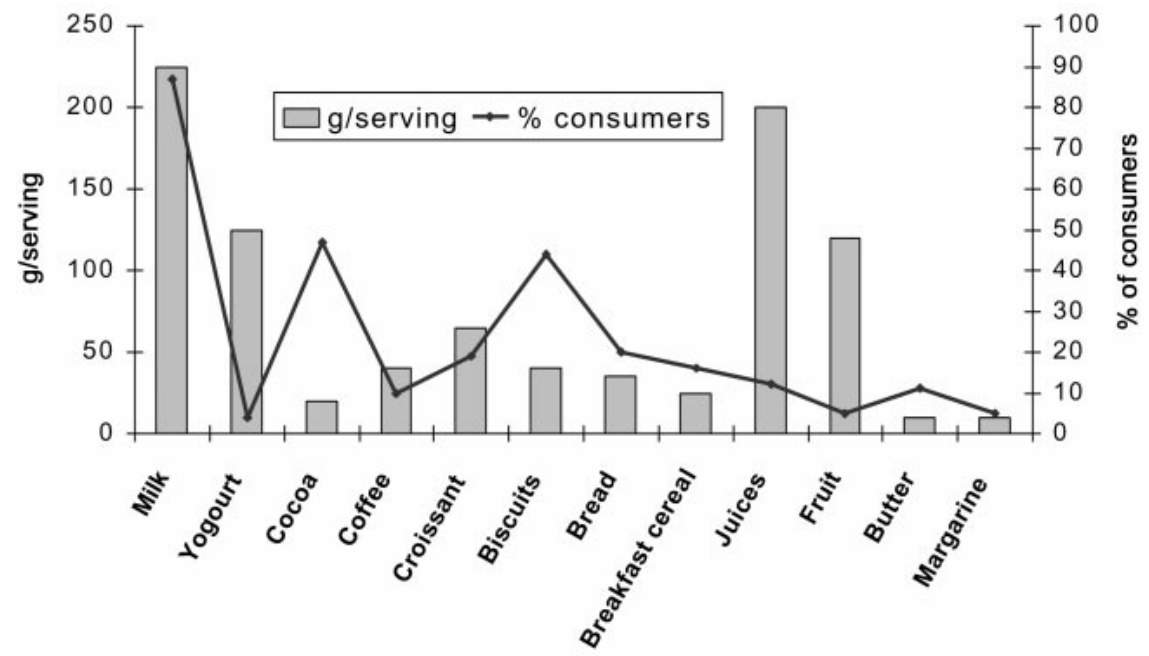

Fig. 1 Foods consumed with breakfast and percentage of consumers in the Spanish population aged 2 to 24 years

and sugar, a choice of either breakfast cereals (34\%), biscuits (40\%), bread (15\%) or sponge, buns, croissants, etc. $(10 \%)$. Some $10 \%$ of the group usually had orange juice for breakfast and 5\% some kind of fruit or fruit salad. Figure 1 shows percentage of consumers by food group for breakfast and average portion size for each food item.

Doughnuts, biscuits, croissants and breakfast cereals, in descending order, were scored highest as preferred foods for breakfast. Girls chose yoghurt, cheese and fruit for breakfast more often than boys.

\section{Quality Breakfast Score}

According to the QBS, 45\% were classified in the 'fair breakfast' group. Boys had higher QBS than girls; younger age groups had better scores than older ones $\left(\chi^{2}=77.26\right.$; $P<0.001)$. Some $44.7 \%$ of the sample were classified in the poor-quality breakfast group (Fig. 2). Only 5\% were classified as having a 'good-quality breakfast'. Fruit was the item missing in more than $70 \%$ of the subjects. Lower socio-economic groups had lower QBS $\left(\chi^{2}=13.16 ; P<\right.$ 0.05). Subjects from families whose parents had lower education level had lower QBS as well $\left(\chi^{2}=21.68 ; P<\right.$ $0.05)$. No significant differences were found between weekdays and weekends for QBS.

A higher proportion of children and youngsters having breakfast alone were classified as 'poor quality' (48\%), particularly during weekdays; the percentage was even higher for girls (56\%). This proportion was significantly lower for those having breakfast with someone else (40\%).
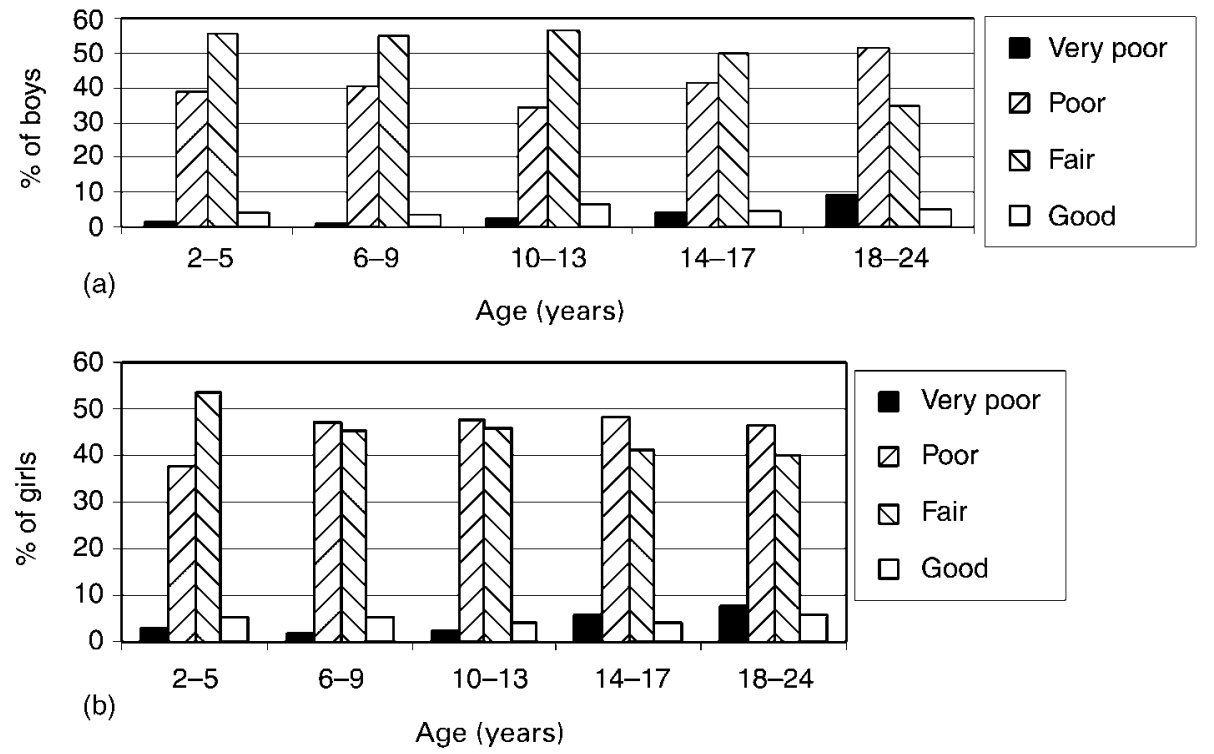

Fig. 2 Distribution of Quality Breakfast Score* by age group in (a) boys and (b) girls (*breakfast quality score considering the number of food items included from the dairy group, cereals and fruit) 
Eight per cent of children having breakfast with their family were classified in the 'good-quality' group; the proportion of children classified in the 'poor-quality' group was significantly lower $\left(\chi^{2}=21.80 ; P<0.01\right)$.

Sixty per cent of the group spent less than 10 minutes having breakfast. Higher QBS was observed among those who spent between 10 and 20 minutes for breakfast.

\section{Breakfast intake and dietary balance}

Some $32 \%$ of the sample had energy intakes with breakfast below $200 \mathrm{kcal}$ and 31.5\% had intakes between 300 and $500 \mathrm{kcal}$, the last range accounting for $19.7 \%$ of total energy intake. People classified in the upper range of energy intake had adequate intakes for calcium, iron, B vitamins and folate $(P<0.05)$. However, average nutrient intakes for those having energy intakes below $200 \mathrm{kcal}$ for breakfast were below RNIs for total energy, calcium, iron, vitamin A and vitamin E. Increasing energy intake with breakfast was significantly associated with adequate micronutrient intakes, particularly when breakfast supplied $500 \mathrm{kcal}$ or more. People having higher energy intakes had a higher percentage of energy from fat as well (39-40\%).

\section{Discussion}

The Iowa Breakfast Study carried out at the beginning of the $1960 \mathrm{~s}^{14}$ raised increasing interest for further research on the role of breakfast in dietary balance, physical and cognitive performance. Many studies concluded that inadequate breakfast intake cannot be compensated for by other intakes during the day in terms of dietary balance $^{1,15}$. The focus for other researchers was the relationship between inadequate or missing breakfast intake and growth, development or even physical and cognitive performance ${ }^{1,5,6}$.

In recent decades, high proportions (20\%) of children and adolescents attending school with no breakfast were described in Spain and other European countries ${ }^{16,17}$ and in the $\mathrm{USA}^{15}$. Hercberg and co-workers ${ }^{17}$ reported that $40 \%$ of people younger than 18 years had inadequate breakfast intakes in Val-de-Marne (France). Children having higher calorie intakes with breakfast showed a higher proportion of total energy from carbohydrates and significantly lower fat intakes. Micronutrient intakes were more adequate for calcium, phosphorus, magnesium, and vitamins $\mathrm{B}_{1}$ and $\mathrm{B}_{2}$.

Nicklas et al. found that $37 \%$ of young adults (18-28 years) in Bogalusa (USA) had no breakfast ${ }^{2,15}$. Only $3 \%$ usually had fruit for breakfast, and $2.5 \%$ had fruit juices. Evaluation of the school breakfast programme in Bogalusa showed that the prevalence of inadequate intake for minerals and vitamins was significantly lower among children having breakfast ${ }^{15}$.

Ortega et al. ${ }^{18}$ described $4 \%$ of non-breakfast consumers in a group of school children in Madrid.
Furthermore, $17 \%$ of the boys and $32 \%$ of the girls only had a dairy product (milk, yoghurt) for breakfast.

The enKid Study is the first nutritional survey carried out in a random sample of the Spanish population aged 2-24 years. Quality control measures through the planning process and fieldwork of the study contribute to improve the accuracy of the results. The enKid Study shows that $8.2 \%$ of Spanish children and young people usually go to school having no breakfast, a higher proportion of females and young people. Although there are no reference data in this regard at country level, regional nutritional surveys in the school-aged population carried out 10-15 years ago suggest a lower proportion of children and young children do not have breakfast before attending to school, compared with previous data ${ }^{16}$. The follow-up of the breakfast programme in school children in Bilbao reported a significant improvement in the proportion of school children having breakfast and energy supplied with this meal between 1984 and $1994^{16}$. School-based educational programmes reinforced by media support and family involvement have played an important role in this respect ${ }^{19}$.

However, a large percentage of Spanish children and young people still have inadequate breakfast intakes. Furthermore, more than $4 \%$ do not eat anything before lunch. Consumption of a balanced breakfast including milk products, cereals and fruit to provide adequate energy intake $-20-25 \%$ of daily energy requirements according to age and physical activity can contribute to healthy dietary patterns, rich in carbohydrates and micronutrients. Thus, school-based nutrition education programmes should be reinforced in every school, involving families, teachers and others, in order to achieve healthier dietary patterns and adequate breakfast consumption in Spanish children and young people, including dairy products, cereal products and fruit.

\section{Acknowledgements}

The authors express their appreciation to all the enKid team investigators, a project funded by Kellogg's España SA and Kellogg's Company (Battle Creek, USA) via the Fundación Universitaria de Las Palmas de Gran Canaria and the Fundación para la Investigación Nutricional. The enKid Study Group comprised the following people: Directors - L Serra-Majem and J Aranceta Bartrina; Coordinators - L Ribas Barba and C Pérez Rodrigo; Collaborators - R García Closas, L Gorgojo Jiménez, L Jover Armengol, J Ngo de la Cruz, L Peña Quintana, A Pérez Rodrigo, B. Román Viñas, G Salvador Castells; Scientific Committee - Á Ballabriga Agudo (Universidad Autónoma de Barcelona), P Cervera Ral (Centre d'Ensenyament Superior de Nutrició i Dietètica (CESNID), University of Barcelona), A Delgado (Universidad del País Vasco), JM Martín Moreno (Escuela Nacional de Sanidad, Madrid), J Mataix Verdú (Universidad de Granada), M 
Moya (Universidad Miguel Hernández) and A Sierra López (Universidad de La Laguna).

\section{References}

1 Ruxton CHS, Kirk TR, Belton NR, Holmes MAM. Breakfast habits in children. Nutr. Food Sci. 1993; 4: 17-20.

2 Nicklas TA, Bao W, Webber L, Berenson GS. Breakfast consumption affects adequacy of total daily intake in children. J. Am. Diet. Assoc. 1993; 93: 886-91.

3 Kennedy E, Davis C. Department of Agriculture School Breakfast Program. Am. J. Clin. Nutr. 1998; 67(Suppl.): 798S-803S.

4 Burghardt JA, Gordon AR, Fraker TM. Meals offered in the National School Lunch Program and the School Breakfast Program. Am.J. Clin. Nutr. 1995; 61(Suppl.): 187S-98S.

5 Pollit E. Does breakfast make a difference in school? J. Am. Diet. Assoc. 1995; 95: 1134-9.

6 Frost Andersen L, Lande B, Botten G, Larsen H, Bjorneboe GE. Scientific data on breakfast and cognitive function among children and adolescents. Scand. J. Nutr. 1995; 39: $73-8$.

7 Liu K, Stamler J, Dyer A, McKeever J, Mckeever P. Statistical methods to assess and minimize the role of intra-individual variability in obscuring the relationship between dietary lipids and serum cholesterol. J. Chronic Dis. 1978; 31(6-7): 399-418.

8 Aranceta J. Importancia del desayuno en la adecuación nutricional. Revista de Nutrición Práctica Dietecom España 1999; (Abril): 23-7.

9 Mataix J, Mañas M, Llopis J, Martínez de Vitoria E. Tabla de Composición de Alimentos Españoles, 3th ed. Granada: Universidad de Granada, 1998.

10 Favier JC, Ireland-Ripert J, Toque C, Feinberg M. Repertoire
Général des Aliments. Table de Composition. Paris: Lavoisier Tec+Doc, 1995

11 Holland B, Welch AA, Unwin ID, Buss DH, Paul AA, Southgate DAT. McCance \& Widdowson's The Composition of Foods, 5th revised and extended ed. Cambridge: Royal Society of Chemistry, 1991.

12 Norusis MJ. SPSS. Professional Statistics 10.0. Chicago, IL: SPSS, Inc., 2000.

13 Centro Superior de Investigaciones Científicas (CSIC). Tablas de Ingestas Recomendadas en Energía y Nutrientes para la Población Española. Madrid: CSIC, Universidad Complutense de Madrid, 1994.

14 Cereal Institute, Inc. A Summary of the Iowa Breakfast Studies. Vol. 3. Chicago, IL: Cereal Intsitute, Inc., 1962; 1-50.

15 Nicklas TA, O'Neil CE, Berenson GS. Nutrient contribution of breakfast, secular trends and the role of ready-to-eat cereals: a review of the data from the Bogalusa Heart Study. Am. J. Clin. Nutr. 1998; 67(Suppl.): 757S-63S.

16 Aranceta Bartrina J, Pérez Rodrigo C, Santolaya Jiménez J, Gondra Rezola J. Evolución de la ingesta dietética aportada con la ración del desayuno en los escolares de Bilbao (1984-1994). Nutr. Clín. 1997; 16: 171-7.

17 Preziosi P, Galan P, Yacoub N, Kara G, Deheeger M, Hercberg S. La consommation du petit déjeuner dans l'étude du Val-de-Marne. 1. Type, fréquence et ration moyenne des principaux aliments consommés. Cah. Nutr. Diét. 1996; 31(Suppl. 1): 2-8.

18 Ortega R, Requejo A, Redondo R, López-Sobaler AM, Andrés P, Ortega A, et al. Influence of fortified breakfast cereals on dietary habits and nutritional status of Spanish schoolchildren. Ann. Nutr. Metab. 1996; 40: 146-56.

19 Aranceta J, Pérez C. Consumo de Alimentos y Estado Nutricional de la Población Escolar de Bilbao. Guias Alimentarias para la Población Escolar. Bilbao: Area de Salud y Consumo, Excmo, Ayuntamiento de Bilbao, 1996. 